\title{
HUBUNGAN KOLABORASI ANTARA PERAWAT DENGAN APOTEKER DALAM MENINGKATKAN KESELAMATAN \\ PASIEN
}

\author{
SRI HARVITA SARI MARPAUNG / 181101125
}

$\underline{\text { Sriharvitaaasm11@gmail.com }}$

\begin{abstract}
ABSTRAK
Latar belakang : Dalam meningkatkan keselamatan pasien perawat berkolaborasi dengan tim medis lainnya salah satunya dengan orang farmasi. Hubungan perawat dengan apoteker merupakan hal yang sangat intim dalam penerapan keselamatan pasien dalam hal pemberian obat kepada pasien. Tujuan : untuk mengetahui hubungan kolaborasi antara perawat dengan apoteker dalam meningkatkan keselamatan pasien di rumah sakit. Metode : literature review dengan pendekatan jurnal atau artikel, buku dan e-book yang relevan dan akurat serta berfokus pada Menjaga Keselamatan Pasien dengan Interprofesional Collaboration. Adapun jurnal atau artikel dan e-book yang digunakan pada literature review adalah jurnal atau artikel dan e-book yang didapatkan dengan menggunakan Google Scholar, Portal Garuda, dan Jurnal Keperawatan Indonesia. Hasil : dapat memberikan informasi mengenai hubungan kolaborasi perawat dengan apoteker dengan peningkatan keselamatan pasien. Pembahasan : hubungan kolaborasi perawat dengan apoteker dalam meningkatkan keselamatan pasien di rumah sakit. Kesimpulan : Keselamatan pasien dapat ditingkatkan melalui beberapa hal salah satunya adalah pengawasan dalam pemberian obat, bagaimana pada dasarnya dalam masa perawatan pasien dalam mengatasi masalah yang dialami oleh pasien obat merupakan hal yang sangat intim dengan pasien. Oleh karena itu, hubungan kolaborasi antara perawat dengan apoteker sangatlah penting dalam perawatan pasien.
\end{abstract}

Kata kunci : perawat, apoteker, keselamatan pasien, obat

\section{LATAR BELAKANG}

Penerapan program keselamatan pasien pada rumah saskit adalah hal yang diprioritaskan oleh pemberi layanan kesehatan. Perawat sebagai salah satu pemberi layanan asuhan keperawtan memiliki tanggung jawab memberikan asuhan keperawatan yang berkualitas salah satunya adalah keamanan dan keselamatan pasien yang baik. Dalam memberikan asuhan keperawatan kepada pasien perawat tidak dapat memaksimalkan pekerjaannya sendiri, perawat harus dapat berkolaborasi dengan pemberi layanan kesehatan lainnya guna meningkatkan pelayanan yang berkualitas dan dapat meningkatkan derajat kesehatan pasien.

Dalam berkolaborasi perawat dengan tim medis lainnya diperlukan komunikasi yang terjalin dengan baik, salah satunya dengan orang famasi 
(apoteker). Hubungan perawat dengan apoteker merupakan hal yang sangat intim dalam penerapan keselamatan pasien dalam hal pemberian obat kepada pasien, apoteker sebagai orang farmasi bertugas meresepkan obat untuk pasien guna membantu mengatasi masalah yang diderita oleh pasien. dalam hal ini perawat dengan apoteker harus memiliki hubungan kolaborasi yang baik sehingga pelayanan yang diberikan kepada pasien adalah layanan yang terbaik.

Selama proses perawatan pasien di rumah sakit, pengobatan merupakan hal yang sangat penting untuk mengatasi masalah yang dialami oleh pasien. Dengan demikian pada penulisan ini akan membahas tentang hubungan kolaborasi antara perawat dengan apoteker dalam meningkatkan program keselamatan pasien di rumah sakit.

\section{TUJUAN}

Tujuan dari penulisan ini adalah untuk mengetahui hubungan kolaborasi antara perawat dengan apoteker dalam meningkatkan keselamatan pasien di rumah sakit.

\section{METODE}

Penulisan ini menggunakan metode literature review dengan pendekatan jurnal atau artikel, buku dan e-book yang relevan dan akurat serta berfokus pada Menjaga Keselamatan Pasien dengan Interprofesional Collaboration. Adapun jurnal atau artikel dan $e$-book yang digunakan pada literature review adalah jurnal atau artikel dan $e$-book yang didapatkan dengan menggunakan Google Scholar, Portal Garuda, dan Jurnal Keperawatan Indonesia.

\section{HASIL}

Hasil dari penulisan review jurnal ini adalah dapat memberikan informasi mengenai hubungan kolaborasi perawat dengan apoteker dengan peningkatan keselamatan pasien.

\section{PEMBAHASAN}

Keselamatan pasien merupakan suatu upaya utnuk menjamin segala tindakan dan aktivitas yang berhubungan dengan pasien yang dilakukan oleh petugas kesehatan agar berlangsung secara aman dan tidak menimbulkan dampak yang dapat membahayakan pasien melalui serangkaian aktivitas yang diatur dalam undang-undang. 
Salah satu prinsip pelayanan kesehatan adalah untuk menyelamatkan pasien sesuai dengan prosedur dan tindakan yang aman serta tak membahayakan pasien maupun petugas kesehatan. Mutu dan keselamatan pasien sejatinya berakar dari pekerjaan sehari-hari dari seluruh staf di unit pelayanannya.

Seperti staf klinis melakukan pengkajian kebutuhan pasien dan memberikan pelayanan. Hubungan kolaborasi antara perawat dengan apoteker sangatlah penting dalam masa perawatan pasien.

Pekerjaan pelayanan ini disupervisi oleh farmasi yang ditunjuk sesuai dengan kemampuan dan pengalaman farmasi tersebut. Sedang farmasi yang di ruang rawat inap yang sering berinteraksi dengan dokter ruangan, perawat dan pasien serta keluarganya idealnya adalah

farmasi yang sudah memiliki kompetensi

farmasi klinik baik lulusan magister farmasi klinik maupun farmasi yang sudah memiliki pengalaman farmasi klinik di ruang rawat inap.

Kompetensi farmasi klinik di ruangan sangatlah diperlukan dan berani memberikan masukan atau rekomendasi kepada para tenaga kesehatan dalam terapi obat berdasarkan evidence based medicine maupun evidence based pharmacy. Komunikasi yang berhasil akan membangun kolaborasi yang baik. Diharapkan dalam kolaborasi ini bisa berdiskusi antara tenaga kesehatan (perawat) dengan farmasi dalam masalah menangani pasien.

Kendala Kolaborasi

Sering kolaborasi apoteker dengan dokter di ruangan tidak berjalan dengan baik karena komunikasi tidak berjalan maksimal. Memerlukan waktu yang cukup panjang agar perawat atau tenaga kesehatan lainnya mempercayai dan mengakui keberadaan dan peran penting apa yang bisa kita berikan untuk pelayanan kesehatan terbaik bagi pasien. Rasa percaya diri yang kurang dari ahli farmasi menjadi salah satu penghambat untuk langkah maju dan berani berkomunikasi dan berkolaborasi. Ahli farmasi ruangan ini harus banyak belajar dari evidence yang ada dan mempelajari berdasar pustaka yang established dan terbaru, kalau dapat memiliki sarana IT (Information Technology) yang memadai agar mudah dan cepat memecahkan masalah yang dihadapinya sehari-hari. 


\section{KESIMPULAN}

Keselamatan pasien merupakan hal prioritas yang sangat diperhatikan oleh rumah sakit saat memberikan layanan kesehatan kepada pasien maupun masyarakat pada umunya. Keselamatan pasien dapat ditingkatkan melalui beberapa hal salah satunya adalah pengawasan dalam pemberian obat, bagaimana pada dasarnya dalam masa perawatan pasien dalam mengatasi masalah yang dialami oleh pasien obat merupakan hal yang sangat intim dengan pasien. Oleh karena itu, hubungan kolaborasi antara perawat dengan apoteker sangatlah penting dalam perawatan pasien.

\section{REFERENSI}

Agus M Hardjana. 2003. Komunikasi Interpersonal dan Intrapersonal. Yogyakarta : Kanisius.

Anita Davis Boykins. 2014. DNSc, FNPBC, PMHNP BC, Core Communication Competencies in Patient-Centered Care. The ABNF Journal/Spring.
Anggarawati, Tuti, Wulan Sari, N, 2016. Kepentingan Bersama Perawat Dokter dengan Kualitas Pelayanan Ke-perawatan. Jurnal Ilmiah Kesehatan Keperawatan. Vol. 12, No. 1. Februari 2016

Arya Reni, Kurniawan Yudianto, Irman Somantri. 2010. Efektifitas Pelaksanaan Komu-nikasi dalam Kolaborasi Antara Perawat dan Dokter di Ruang Rawat Inap Rumah Sakit Umum Sumedang. Jurnal unpad.ac.id/mku/article. Vol. 12, No. 1 Maret 2010September 2010 Hal 36, Faluzi, A., Machmud, R., \& Arif, Y. (2018). Analisis penerapan upaya pencapaian standar sasarang keselamatan pasien bagi profesional pemberi asuhan dalam peningkatan mutu pelayanan di rawat inap rsup Dr. M. Djamil padang tahun 2017. Jurnal Kesehatan Andalas. 7(4): 34-42.

Fatalina, Femy, dkk. (2015). Persepsi dan Penerimaan Interprofessional Collaborative Practice Bidang Maternitas pada Tenaga Kesehatan. Jurnal 
Pendidikan

Kedokteran

Indonesia. $\quad 4(1): \quad 28-36$.

Firawati.,Pabuty,A.,Putra,A.S.(2012).Pe

laksanaan Program Keselamatan

Pasien Di RSUD Solok: Jurnal

kesehatan masyarakat.6,(2):73-

78.

Gustantini, L. M. \& Mubasyir H. (2014). Upaya Manajemen Rumah Sakit dalam Mendukung Kolaborasi Antara Dokter Umum dan Spesialis di Instalasi Gawat Darurat. Jurnal Manajemen Pelayanan Kesehatan. 17(1): 37-44.

Ismainar, H. (2015). Keselamatan pasien di rumah sakit . Yogyakarta : Deepublish Publisher.

Simamora, R. H. (2019). Documentation of patient Identification into the Electronic System to improve the quality of nursing services. Internasional
Journal of Scientific \& Technology Reasearch.

Simamora, R. H. (2019). The influence Of Training Handover based SBAR Communication for improving patients Safety. Indian journal of public Health

Tutiani. (2017). Manajemen Keselamatan Pasien. Jakarta.

Utama, J. S. A. (2013). Gambaran perbedaan nilai-nilai kerja antara dokter dan perawat di rumah sakit. Jurnal Psikologi. 40(2): 211-225.

Utami, L. dkk. (2016). Hubungan Antara Sikap dan Perilaku Kolaborasi dan Praktik Kolaborasi Interprofessional di Ruang Rawat Inap Rumah Sakit Panti Rapih. Jurnal Keperawatan Muhammadiyah. 1(1): 7- 15. 